\title{
DEMANDA POR FUTEBOL NO BRASIL E NA INGLATERRA
}

\author{
DEMANDA POR FUTEBOL NO BRASIL E NA INGLATERRA
}

Recebido em 23.05.2014. Aprovado em 12.05.2015

Avaliado pelo sistema double blind review

DOl: http://dx.doi.org/10.12712/rpca.v9i2.454

\section{Bruno Ítalo Lima Benevides}

brunoitalobenevides@yahoo.com.br

Universidade Federal do Ceará, Fortaleza/CE, BRASIL

\section{Sandra Maria Dos Santos}

smsantosufc@gmail.com

Universidade Federal do Ceará, Fortaleza/CE, BRASIL

\section{Augusto Cézar de Aquino Cabral \\ cabral@ufc.br \\ Universidade Federal do Ceará, Fortaleza/CE, BRASIL}

\section{Renata Aquino Ribeiro \\ raquino@gmail.com \\ Universidade Federal do Ceará, Fortaleza/CE, BRASIL}

\section{Natália Louisa de Souza Holt}

natalia holt@hotmail.com

Universidade Federal do Ceará, Fortaleza/CE, BRASIL

\section{Resumo}

A indústria do futebol compreende uma gama de setores, visando adquirir insumos, transformá-los em produtos e distribuí-los. Considerando a cadeia produtiva do futebol, este estudo busca comparar os fatores que determinantes da demanda por futebol no Brasil e na Inglaterra, já que a Inglaterra detém 30\% do PIB do futebol, enquanto Brasil possui menos de 1\%. Foram utilizados dados secundários a partir do IBGE, do Office for National Statistics (ONS), da CBF, Pluri Consultoria, da BBC Sports Survey e do site Worldfootball. A pesquisa faz uma análise a partir dos 380 jogos ocorridos na temporada de 2013, tanto no Brasil quanto na Inglaterra. Para estimação da equação de demanda, usou-se o método de Mínimo Quadrado de Dois Estágios. O modelo teve como variável dependente o público pagante nos estádios. Os resultados evidenciaram que fatores econômicos e estruturais e qualidade da partida mostraram-se significantes para explicar a demanda no Brasil e Inglaterra. Destaca-se ainda que clubes ingleses são mais eficientes no que diz respeito a formar preços.

Palavras-chave: Cadeia produtiva. Futebol Demanda.

\section{Abstract}

The football industry comprises a wide range of sectors, aimed at acquiring inputs, transforming them into products and distributing them. Considering the soccer productive chain, this paper seeks to compare the determinants factors of the demand for football in Brazil and England, because this one get 30\% of football GDP while Brazil has less than 1\%. Secondary data were used from IBGE, Office for National Statistics (ONS), CBF, Pluri Consultoria, BBC Sports Survey and from the Worldfootball site. The survey makes an analysis based on the 380 games that occurred in the Brazilian and English championship, 2013 season. To estimate the demand equation, the Two Least Square Stage model was used. The model had as dependent variable the attendance in the stadiums. The results showed that economic and structural factors as well as the quality of the game were significant to explain the demand in Brazil and England. It was also found out that English teams are more efficient in terms of forming prices.

Keywords: Supply chain. Soccer. Demand. 


\section{Introdução}

A indústria do futebol chega a movimentar em todo mundo, por ano, um valor entre U\$\$ 400 bilhões e US\$ 1 trilhão, o que representa cerca de $18 \%$ e $44 \%$, respectivamente, do PIB brasileiro (BELO E PAOLOZZI, 2013). Contudo, no Brasil, apesar de sua imensa popularidade, este esporte movimenta, segundo relatório da Pluri Consultoria (2012), cerca de R \$ 36 bilhões por ano, o que representa menos de $1 \%$ do valor global, enquanto na Inglaterra o valor chega a ser de $30 \%$. Portanto, no Brasil, como atividade econômica, o futebol está longe de ter sua eficiência maximizada, mesmo sendo reconhecido como o esporte da nação.

Os dados apresentados sugerem que há no Brasil um grande potencial econômico a ser explorado no futebol. A dinâmica dessa indústria e seus reflexos na economia devem ser compreendidos a partir da análise de toda a cadeia produtiva que envolve o futebol (BLUSCHMEIN; NEDAL, 2010). Por cadeia produtiva, pode se entender o processo integrado de setores que agem conjuntamente com o objetivo de adquirir insumos, transformá-los em produtos e distribuí-los aos consumidores (BEAMON,1998). No caso da indústria do futebol, o jogo é o produto final da cadeia produtiva e o torcedor é o consumidor final. Há, ainda, nesta cadeia, outros agentes importantes, tais como investidores, emissoras de televisão, empresas de marketing, etc., considerados consumidores intermediários, que intermediam o mercado produtor, constituído por clubes e federações, ao mercado consumidor (LEOCINI; SILVA, 2003).

Para Ekelund (1998), o torcedor é o principal elo da cadeia, pois é a partir dele que surgem os consumidores intermediários. Bluschmein (2013) corrobora a importância deste elo na cadeia produtiva do futebol, mostrando que o torcedor tem participação de aproximadamente $46 \%$ no valor total gerado pela cadeia.

Em geral, quando se quer avaliar a potencialidade econômica de um determinado setor, analisa-se o número de consumidores e a propensão que os mesmos têm a consumir do bem produzido pela indústria em questão. Deste modo, fica evidenciada a relevância de se analisar o comportamento do consumidor de futebol e entender os fatores que o levam a demandar este bem, para que desta forma essa indústria possa funcionar de maneira mais eficiente, na perspectiva econômica.

Com relação à procura pelo bem futebol, diversos pesquisadores têm baseado seus estudos, tendo o público presente nos estádios como proxy para a demanda do torcedor. E, como fatores explicativos da procura por jogos, utilizam fatores econômicos e estruturais, incerteza de resultado e qualidade esperada da partida. No Brasil, destacam-se os trabalhos de Souza (2004), Madalozzo (2008), Bortoluzo, Laropoli e Machado (2011). Na Inglaterra, Dobson e Goddard (2001), Forrest e Simmons (2006), Buraimo e Simmons (2009) e O'Connor (2009). Um dos pontos de destaque nestes estudos é a constatação que há diferença significativa entre os consumidores brasileiros e ingleses no que tange aos aspectos de incerteza do resultado e qualidade esperada. Estes estudos mostram que, no Brasil, o torcedor é mais sensível a estes fatores do que na Inglaterra.

Dado que o público presente nos estádios é tido como proxy da procura por futebol e que, segundo O'Connor (2009), esse público representa uma das principais fontes de receitas dos clubes de futebol, é importante relacionar a demanda com receita. No Brasil, a receita dos clubes, proveniente do consumo dos torcedores em dias de jogos, chega a representar $7 \%$ da receita total, enquanto na Inglaterra essa receita é cerca de 23\%, de acordo com estudo da Delloit (2013). Enquanto isso, a demanda por jogos no Brasil é cerca de 60\% menor que na Inglaterra.

Sabendo-se, então, que o futebol inglês detém 30\% da produção total dessa indústria, um valor bem maior que no cenário brasileiro, e que há uma diferença significativa, entre Brasil e Inglaterra, na composição da receita dos clubes advinda de bilheteria, é importante identificar os fatores determinantes da demanda que diferenciam o comportamento dos torcedores e dos times nestes dois países. Assim, a principal questão deste trabalho é: quais os determinantes da demanda por jogos de futebol no Brasil e na Inglaterra?

Tem-se as seguintes hipóteses: i) a qualidade dos times visitantes afetam mais os torcedores brasileiros que os ingleses; ii) a elasticidade-preço da demanda é mais próxima da margem de maximização de receita na Inglaterra.

Como objetivo geral, este trabalho visa a identificar os fatores que determinam a demanda por jogos de futebol no Brasil e na Inglaterra. Como objetivos específicos tem-se: i) identificar de que maneira os fatores econômicos afetam a demanda por futebol nos dois países, ii) verificar os impactos referentes à qualidade da partida, substitutos e estruturais e iii) 
comparar o comportamento dos clubes brasileiros e ingleses como agentes maximizadores de lucro.

O estudo utiliza-se de um modelo econométrico, em alinhamento ao argumento de Souza (2004) de que pesquisas envolvendo a demanda por jogos de futebol seguem um padrão, em que tal modelo é formulado para tentar explicar a demanda de acordo uma série de fatores. Em termos de estrutura, além desta introdução, este artigo tem quatro outras seções. A seção 2 apresenta pesquisas desenvolvidos na área da Economia do esporte, com uma subseção sobre o futebol como um negócio e outra com estudos sobre a demanda por futebol. A seção 3 traz a metodologia utilizada, enquanto que a seção 4 faz uma análise dos resultados obtidos. Por fim, a seção 5 apresenta as conclusões do estudo.

\section{Contextualização histórica}

Não há um consenso de onde surgiu o futebol, mas, segundo Russell (2006) já no século II ou III a.C, durante a dinastia Han, os chineses praticavam um esporte em que tinham que chutar uma bola dentro de uma pequena rede. Um esporte similar ao futebol era praticado por gregos e romanos antigos, em que 27 jogadores incorporavam cada time, diferentemente de hoje, em que 11 jogadores compõem cada lado.

Já na Inglaterra, de acordo com Dobson e Goddard (2001), o futebol originou-se na Idade Média. Sendo originalmente um jogo duro e violento, envolvendo um número não especificado de jovens homens perseguindo uma bola através de localidades urbanas e rurais, frequentemente resultando em sérios danos às propriedades, lesões e até morte.

Para Dobson e Goddard (2001) essa profissionalização foi o elemento chave no processo que culminou na formação da Football League, em 1888. A Football League era composta inicialmente por 13 clubes ingleses.

No Brasil o futebol chegou através de Charles Miller, que ao retornar de seus estudos na Inglaterra, trouxe em sua mala camisa, calções, chuteiras e duas bolas oficiais. O primeiro jogo, em solo brasileiro, foi promovido por ele no dia 14 de abril de 1895, uma manhã de domingo, em um terreno baldio da várzea do Carmo, em São Paulo (MÁXIMO,1999).

De acordo com Brustolin (2008, p.24):

Em 1914, surge a Federação Brasileira de Sports, e em 1916 a Confederação Brasileira de Desportos (CBD), que dedicou- se aos esportes amadores. Em 1923, foi criada a Federação Brasileira de Futebol para os adeptos do profissional. Somente em 1937, a Federação Brasileira de Futebol uniu-se à Confederação Brasileira de Desportos, dando início à fase profissional do futebol.

Desde então surgiram campeonatos nacionais como Taça Brasil (1959-1968), Torneio Roberto Gomes Pedrosa (1967-1970), Copa do Brasil (1989-presente) e o Campeonato Brasileiro (1971-presente).

A partir da década de 1970, como bem afirmam Dobson e Goddard (2001), os primeiros estudos dentro da economia do futebol focaram principalmente em identificar a demanda por jogos desse esporte. Estes autores creditam a Hart, Hutton e Sharot (1975) o pioneirismo em estudos sobre demanda por futebol na Inglaterra, que levariam a demais pesquisas na área desde então.

Já a partir da década de 1990, de acordo com Dobson e Goddard (2001) a vasta gama de artigos publicados sobre economia do futebol, atraiu a atenção de vários economistas europeus, principalmente, que começaram a analisar não só a demanda, mas também o mercado de trabalho, salário e transferências dos jogadores de futebol, além das implicações da criação do campeonato europeu de clubes (Champions League) no balanço competitivo do futebol europeu.

\section{A economia do futebol}

O interesse acadêmico na economia do esporte de times profissionais data de meados da década de 1950, quando Rottenberg (1956) analisou o mercado de trabalho do baseball americano. Desde então, vários livros e artigos foram publicados a respeito. Nesta seção, tendo em vista o objeto do estudo, são apresentadas pesquisas sobre o futebol como um negócio, a ser compreendido em termos de sua cadeia produtiva, e sobre a demanda por jogos de futebol.

\section{O futebol como negócio}

O futebol como negócio é um mercado em evolução. A transformação dos clubes, de instituições sem fins lucrativos em empresas comerciais, ocorreu, prioritariamente, na Europa a partir da década de 1980 (AIDAR; FAULIN, 2013). O processo de empresarização do futebol envolve toda uma cadeia produtiva, constituída por uma complexa rede de relacionamentos interorganizacionais, tendo o 
torcedor como elo final e de relevância essencial, como atestam diversos estudos (SANTANA; SOBRINHO, 2008, 2010; FAGUNDES; VEIGA, 2013; FLEURY et al., 2013; SANTOS, 2013).

Tomando por base Solé (2008), Rodrigues, Silva e Dellagnelo (2014) analisam o processo de empresarização em organizações esportivas e religiosas localizadas no Brasil, utilizando as dimensões de orientação mercadológica, aspectos legais, linguagem e organização do trabalho. Os autores constataram que, dentre as organizações culturais estudadas, os clubes de futebol são as organizações que apresentaram o processo de empresarização mais intenso e avançado, nas quatro dimensões consideradas. Estes resultados corroboram a argumentação desenvolvida neste trabalho, a perspectiva da indústria do futebol, cuja dinâmica pode ser compreendida a partir da concepção de cadeia produtiva.

Além dos jogadores e técnicos, esta cadeia inclui fabricantes de mercadorias dos clubes, consultorias de marketing esportivo, patrocinadores e, dentre outros, serviços de mídia e de licenciamento (DUCREY et al., 2003). Desta cadeia, participam, ainda, instituições e agentes, tais como (AIDAR; LEONCINI, 2000, p. 81):

- agrupamentos esportivos (clubes, ligas privadas, Confederação Brasileira de Futebol-CBF, etc.);

- $\quad$ produtores e vendedores de bens necessários à prática do esporte (equipamentos esportivos, como chuteiras - Nike, Adidas etc.);

- $\quad$ produtores e vendedores de serviços diretos necessários à prática do esporte (professores, treinadores, médicos especialistas; etc.) e,

- produtores e vendedores de espetáculos esportivos e bens associados (fotos dos campeões, loteria esportiva, transmissões pela TV, etc.).

A prática e o consumo de tudo que é relacionado ao futebol é possível graças ao conjunto dos atores desta cadeia produtiva. A relevância financeira deste mercado pode ser dimensionada em $\mathrm{R} \$ 3,5$ bilhões anuais somente no Brasil (BLUMENSCHEIN, 2013).

Por sua relevância socioeconômica e cultural, diversas facetas do negócio do futebol têm sido objeto de pesquisa. No Brasil, dentre os estudos sobre mercado de futebol, merece destaque a tese de Leoncini (2001), que traz o desenho de uma cadeia produtiva do esporte. Mosca, Silva e Bastos (2009) afirmam que fatores institucionais e organizacionais, como as instituições e empresas com que os clubes se relacionam, afetam o mercado de futebol. Valente e Serafim (2006) ressaltam a relevância da profissionalização dos clubes, propondo novos modelos de gestão para o futuro do mercado de futebol brasileiro. Em outros estudos, tais como Carvalho, Gonçalves e Alcântara (2003), Rodrigues e Silva (2007) e Reale, Dalmoro e Segabinazzi (2013), o foco é na inter-relação entre clubes e empresas que atuam no setor, como, por exemplo, fabricantes de produtos esportivos e emissoras de rádio e televisão. Grellet (2010) aponta o futebol como um símbolo de diversas transformações econômicas pelas quais o Brasil passa, inclusive no tocante ao mercado de esportes.

A indústria do entretenimento representa um setor cada vez mais importante da economia de serviços e o esporte toma cada vez sua fatia (LEONCINI, 2001). Nesta perspectiva, Moura e Lucian (2008) argumentam que o aumento da lucratividade do mercado de futebol no Brasil acontecerá, dentre outros caminhos, com o crescimento do interesse do torcedor brasileiro que associará cada vez mais um jogo de futebol a uma experiência de consumo extraordinária, assim como acontece na Inglaterra, em que ir ao estádio nos fins de semana é comparado a ir ao shopping (LEONCINI, 2001).

A receita dos 20 maiores clubes do mundo cresceu 8\% para 5,4 bilhões de euros em 2013 (DELOIT'TE, 2014). Essas receitas podem ser examinadas com base em várias métricas como números de bilheteria, quantidade de fãs, audiência em TV, patrocínios, mercadorias com a marca do clube e muito mais.

Barajas, Fernandez-Jardon e Crolley (2005) traçam uma relação entre o bom desempenho de clubes em um campeonato e a melhoria dos resultados financeiros para as empresas esportivas. Como forma de compreender o potencial de lucratividade do mercado do futebol, Borland (1987) busca traçar o perfil do consumidor de futebol, investigando a renda dos torcedores e sua relação com o preço dos ingressos nos estádios.

Buraimo e Simmons (2009) argumentam que a probabilidade de um clube vencer jogos é ligada aos investimentos que realiza, como a aquisição de novos jogadores. A quantidade de investimentos serve, ainda, para dimensionar o mercado de futebol em que o time atuará, sendo a busca pelas maiores ligas, 1a divisão dos campeonatos.

Dell'osso e Szymanski (1991) afirmam que os contratos com outras empresas que um clube pode realizar são essenciais para seu sucesso, incluindo 
emissoras de TV e organizações como representantes da liga de clubes. Ser um grande clube significa ter uma rede de apoio contínua, principalmente de torcedores dispostos a pagar para assistir as partidas nos estádios ou através de outros meios promocionais.

O exame da literatura evidencia que o mercado de futebol profissional oferece oportunidades de pesquisa da cadeia produtiva com relação a elementos como o comportamento do consumidor, economia do trabalho, organização industrial e outros tópicos mais específicos (DOBSON; GODDARD, 2004). Constata-se que a importância do futebol é econômica, social e cultural, determinada por milhões de torcedores assistindo a partidas na TV ou indo até os estádios.

\section{Estudos sobre a demanda por futebol}

Demanda é a quantidade de um bem que os consumidores desejam consumir a um determinado preço; contudo, a quantidade demandada de um bem pode não depender apenas do preço, mas também de outras variáveis (PINDYCK; RUBINFELD, 2009). Renda é uma variável importante, pois, com uma renda maior, os consumidores poderão adquirir mais bens. Em relação aos jogos de futebol, além do preço e da renda, como afirma Souza (2004), aspectos referentes à partida como desempenho recente dos times, estrutura do estádio e horário em que essa ocorre, também são importantes para explicar a procura por esse bem.

Nos estudos sobre a demanda por futebol, Dobson e Goddard (2001), Forrest e Simmons (2006), Buraimo e Simmons (2006) e O'Connor (2009) estimaram uma equação de demanda para o campeonato inglês. Para o campeonato brasileiro, Souza (2004), Madalozzo (2008) e Bortoluzzo, Laropoli e Machado (2011) também fizeram esta estimação.

Dobson e Goddard (2001) estimaram um modelo buscando explicar as variações nas médias de público, por temporada, ao nível de clube do campeonato inglês, incluindo as quatro divisões, entre as temporadas de 1947 e 1997. Os autores modelaram a demanda em dois momentos. No primeiro, o modelo foi estimado utilizando dados em painel.

The model's coefficients reflect the influence of four factors upon demand: loyalty in the short-term (or persistence in attendance from year to year), success (measured by league position), admission price and entertainment (proxied by goals scored) (DOBSON; GODDARD, 2001, p. 342).
Já no segundo momento, os autores tentaram explicar "... the cross-sectional variation between clubs in their base levels of attendance, and their short-term loyalty, success, price and entertainment coefficients obtained at the first stage." (DOBSON; GODDARD, 2001, p. 343). Nesta etapa, os autores usaram como variáveis explicativas características socioeconômicas e demográficas da cidade de cada clube. Foram utilizadas, por exemplo, o tamanho da população, a estrutura ocupacional e o desemprego além de características relacionadas ao futebol, como a idade do time e o número de outros times na mesma cidade.

Os resultados obtidos pelos autores no primeiro estágio mostraram-se significantes ao nível de 5\%, exceto a variável referente aos gols marcados, que mostrou-se insignificante no modelo. Dobson e Goddard (2001) ainda concluem que devido ao fato de o público estar em logaritmo e todas as variáveis estarem padronizadas, os coeficientes estimados não têm uma interpretação direta. Assim, pode-se concluir que os resultados obtidos apenas mostram se os fatores que buscam explicar a demanda têm impacto positivo ou negativo, sem, contudo, fornecer a elasticidade destes fatores.

No segundo estágio, Dobson e Goddard (2001) utilizaram como variáveis explicativas o logaritmo natural da população e do número de anos do clube. Foram utilizados também o número de outros clubes presentes na mesma cidade, a porcentagem de empregados na agricultura, assim como a porcentagem de empregados nos setores de energia, manufatura e construção. Além disso, foi utilizado o número de homens com idade entre 16-64 anos desempregados. Como variáveis independentes, os autores utilizaram o público, preço, lealdade no curto prazo, posição na liga e gols marcados. Os resultados foram todos significantes ao nível de $5 \%$.

Para estimar a demanda do campeonato inglês, Buraimo e Simmons (2006) também utilizaram um modelo econométrico, em que a procura por jogos é função de seis grupos de fatores: fidelidade ao time, a qualidade dos times envolvidos na partida, incerteza do resultado, tamanho do mercado, competição e mídia. Os autores estimaram o modelo econométrico utilizando TOBIT e obtiveram resultados estatisticamente não-significantes apenas para as variáveis referentes à qualidade dos times envolvidos na partida, como idade do time visitante, bem como seu número de pontos, e referente à mídia, como partidas transmitidas no Bank Holiday, e período em que a partida ocorreu. 
O'Connor (2009) buscou estimar a lealdade dos torcedores ingleses utilizando uma equação de demanda, para verificar se fatores como o momento atual do time, como promoções para outras divisões afetam a procura por jogos. Como variável dependente, utilizou a porcentagem de lotação do estádio, dada pela relação entre público presente e capacidade do estádio.

O'Connor (2009) não dividiu os fatores explicativos da demanda em grupo. Utilizou-se das seguintes variáveis: a posição do time até a data de realização da partida, o preço dos ingressos, o número de gols que time tenha tomado nos últimos três jogos, bem como tenha feito, a porcentagem de jogos já realizados no campeonato, o quadrado da posição do time, quadrado da porcentagem de partidas realizadas e dummies para caso o time tenha sido promovido, rebaixado, vencido pelo menos um dos últimos três jogos, perdido pelo menos um dos últimos três jogos, se o jogo foi realizado na semana e por último, se envolvia times rivais.

$\mathrm{O}$ autor estimou o modelo de três maneiras, efeitos fixos, aleatórios e mínimos quadrados. Os dois primeiros modelos mostraram resultados semelhantes, sendo estatisticamente significante a porcentagem de jogos já realizados, o quadrado da porcentagem de jogos realizados, rebaixamento, promoção, partida realizada em dias de semana e envolvendo rivais. Já pelo método de $\mathrm{MQO}$, apenas promoção, partidas envolvendo rivais e a porcentagem de jogos já realizados foram significantes.

Já Souza (2004) objetivou verificar os fatores mais importantes que influenciam na decisão dos torcedores em comparecerem aos estádios, fazendo uma análise do campeonato brasileiro de 2002. O autor também verificou se os jogos televisionados constituem um bem substituto dos jogos nos estádios de futebol e tentou medir as elasticidades preço e renda da demanda.

Souza (2004) também se utilizou de um modelo econométrico, em que a variável dependente consiste no público pagante de cada partida. Quanto às variáveis explicativas, o autor as divide em seis grupos de fatores que influenciam a demanda: fatores econômicos, demográficos, desequilíbrio competitivo, qualidade esperada da partida, substitutos e atributos dos clubes. $\mathrm{O}$ autor estimou seu modelo de três formas, uma linear, outra log-linear e uma log-log. Segundo o autor, o modelo linear apresenta vários problemas, como heterocedasticidade e não normalidade dos resíduos, além de revelar erro de especificação. O modelo log-log foi testado para capturar a elasticidade da renda. Foram obtidos resultados significantes ao nível de 5\% para as variáveis, exceto aquelas referentes ao desemprego e as partidas televisionadas. Sobre a elasticidade renda da demanda, Souza (2004) conclui que os jogos do campeonato brasileiro de 2002 são bens inferiores, apresentando uma elasticidade de -3,67.

Conforme Madalozzo (2008), a demanda por jogos é frequentemente alvo de estudos na economia dos esportes. A abordagem mais comum é uma equação de demanda com fatores econômicos e sociais que determinam a procura para cada tipo de esporte.

Em seu estudo, Madalozzo (2008) investigou os fatores que afetaram a demanda por jogos do campeonato brasileiro entre 2003 e 2006. Tendo analisado 1946 jogos, a autora usou o logaritmo do público pagante como variável dependente. $\mathrm{O}$ modelo foi estimado usando dados em painel com efeitos fixos e aleatórios. A autora também dividiu os fatores que afetam a demanda em grupos, sendo eles: características estruturais, qualidade esperada, performance e incerteza do resultado.

Os modelos estimados por efeitos fixos e aleatórios tiveram resultados similares. Em ambos, as variáveis referentes ao grupo estrutural mostram-se ser significantes a $5 \%$, exceto para o número de jogos disputados pelo time da casa no último mês. Além disso, a renda não foi estimada por efeito fixo, apenas aleatório, apresentando uma elasticidade de - 0,7 , mostrando que o futebol é um bem inferior. Já o preço obteve valor igual para os dois modelos, tendo uma elasticidade de -0,24, o que implica, segundo a autora, que considerando cada time como monopolista, este não é maximizador de lucro.

Nos fatores referentes à qualidade esperada da partida, as variáveis alusivas aos títulos estaduais e títulos internacionais no ano anterior mostramse insignificantes. Neste grupo, a variável relativa à rivalidade mostrou ter um impacto de 0,63 na demanda por jogos do campeonato brasileiro. No grupo performance, apenas a variável referente aos pontos ganhos pelo time visitante nos últimos três jogos mostrou-se insignificante. Já no grupo incerteza, a diferença entre a posição dos times adversários e a chance de ir para copa libertadores obtiveram resultados insignificantes.

Bortoluzzo, Laropoli e Machado (2011) examinaram a demanda por jogos do campeonato brasileiro de futebol da série A no período de 2004 a 2009, também 
usando o público pagante como variável dependente e estimando o modelo por TOBIT. Os dados são de 2481 jogos do campeonato brasileiro da primeira divisão. Como variáveis independentes, usaram a renda per capita anual da cidade em que o jogo ocorreu, a população da respectiva cidade, classificação do time da casa e do time visitante, pontos ganhos pelo time da casa e visitante nos últimos três jogos, gols marcados pelo time mandante e visitante nas três partidas anteriores, preço médio (dado pela razão entre a arrecadação e o público pagante), dummies para: estação do ano, caso o jogo tenha ocorrido no fim de semana, caso tenho chovido, se o jogo foi realizado às 21:00h, se o jogo é considerado clássico, se há time de São Paulo ou Rio de Janeiro e se o jogo foi disputado no início, meio ou fim do campeonato.

Cinco variáveis do modelo mostraram-se insignificantes: pontos ganhos pelo time visitante nas últimas três partidas, gols marcados pelo time visitante nos últimos três jogos, dummy para o caso de o jogo ter ocorrido às 21:00h, dummy para o caso de o jogo ter ocorrido no inverno e dummy para o caso de o jogo ter ocorrido na primavera. Com relação às variáveis econômicas, os autores encontraram uma elasticidade-preço de -0,21 e uma elasticidade-renda da demanda de $-0,47$.

Nota-se nesta seção que fatores econômicos, estruturais e de qualidade da partida são comuns nos estudos sobre a demanda por futebol.

\section{Metodologia}

Essa seção trata dos aspectos metodológicos do estudo, enfatizando a tipologia da pesquisa, base de dados utilizada e o modelo econométrico que deu suporte ao trabalho.

\section{Tipologia de pesquisa}

A pesquisa é de natureza explicativa e descritiva. Quanto ao caráter explicativo, esse tipo de pesquisa "tem como propósito identificar fatores que determinam ou contribuem para a ocorrência dos fenômenos" (GIL, 2010, p.43). Sendo assim, dado que se busca verificar os fatores determinantes da demanda por jogos do campeonato brasileiro de futebol da série A de 2013 e da Premier League inglesa, justifica-se o caráter explicativo do estudo. A natureza descritiva decorre do fato de que "visa descrever as características de determinada população ou fenômeno ou o estabelecimento de relações entre as variáveis." (SILVA; MENEZES, 2001, p.21). Nesse contexto, esta pesquisa é descritiva, pois faz uma descrição das características daqueles fatores.

Além disso, trata-se de um estudo quantitativo, haja vista que os dados utilizados receberam tratamento estatístico (RICHARDSON, 2007) que possibilitaram verificar os determinantes que afetam a demanda por jogos do campeonato brasileiro da série A e da Premier League inglesa.

\section{Base de dados}

Esta pesquisa se baseia em dados secundários gerados a partir do banco de dados do Instituto Brasileiro de Geografia e Estatística (IBGE), do Office for National Statistics (ONS), Confederação Brasileira de Futebol $(\mathrm{CBF})$, Puri Consultoria, Cadastro Nacional de Estádios de Futebol, do BBC Sports Survey e do site Worldfootball, através da internet em seus respectivos sites oficial. A pesquisa faz uma análise a partir dos 380 jogos ocorridos na temporada de 2013, tanto no Brasil quanto na Inglaterra. Todos os dados desta pesquisa são referentes ao ano de 2013, exceto o rendimento médio dos domicílios, disponibilizado pelo IBGE, que é referente ao ano de 2010.

\section{Modelo econométrico}

Como afirma Souza (2004), pesquisas envolvendo a demanda por jogos de futebol seguem um padrão, em que um modelo econométrico é formulado para tentar explicar a demanda de acordo uma série de fatores. Tal argumento é reforçado por Dobson e Goddard (2001), ao afirmarem que muitos estudos analisam o público, estimando um modelo de regressão e interpretando o resultado como uma equação de demanda. Nesta linha de ação, este estudo, também, utiliza-se de um modelo econométrico.

A variável dependente utilizada no estudo é dada pelo número de pagantes de ingressos para jogos do campeonato brasileiro. No caso da Inglaterra, segundo estudo da Delloit (2012), apenas 30\% da composição do público presente nos estádios é de torcedores que compraram ingressos apenas para o jogo em questão, não sendo "season tickets". Desta forma, a variável dependente para o futebol inglês consiste em 30\% do público presente no estádio. Ambas foram postas sobre a forma logarítmica, sob a hipótese de não linearidade com as variáveis independentes. A variável 
"público pagante" é usada, pois "provide the main source of data for the dependent variable in econometric models of the demand for football attendance" (DOBSON; GODDARD, 2001, p. 319).

Quanto às variáveis explicativas, parte-se do pressuposto que a demanda é função de quatro grupos de fatores, sendo eles: econômicos, de qualidade esperada da partida, substitutos e estruturais. Devido à limitação de dados disponíveis à época desta pesquisa, algumas variáveis incluídas nestes grupos não são compatíveis entre Brasil e Inglaterra.

Entre os fatores econômicos, foi utilizado para o Brasil o logaritmo de preço médio, dado pela razão entre arrecadação e público pagante. Já para Inglaterra, essa variável foi medida pelo chamado club day match, que consiste no valor do ingresso, acrescentado o valor da torta e do chá. Ainda neste grupo de fatores, foi utilizado o rendimento médio das famílias na cidade em que a partida ocorreu.

Já no grupo de fatores relacionados à qualidade esperada da partida para o futebol brasileiro, estão as variáveis: Rival, Vitória, Grande, Promovido, Rodada, Posição, Pontos, Pontos2, Amplitude, Amplitude2 e Libertadores. Para Inglaterra, foram utilizadas as mesmas variáveis, excetuando-se Libertadores e acrescentando-se a variável Champions.

No grupo de substitutos para o Brasil, foi utilizada a variável PFC, enquanto para Inglaterra foi utilizado o logaritmo do preço do ingresso para o cinema.

Por último, entre os fatores estruturais estão as variáveis Log (Capacidade), Log (Torcida), Arenas e Log (Passagem) para o Brasil. Enquanto para Inglaterra foram utilizadas as mesmas variáveis utilizadas para o Brasil, excetuando-se Arenas, Log (Torcida) e Log (Passagem) e adicionando-se Log (pie).

Com relação às variáveis econômicas preço e renda, são utilizadas com base na teoria microeconômica, pois, como afirmam Pindyck e Runbifeld (2009), estes fatores são determinantes da demanda dos consumidores.

Os times rivais se encontram em um mesmo território, como cidade ou estado. Assim, será utilizada uma dummy com valor 1 caso os times sejam da mesma cidade e 0 caso contrário. Esta variável será utilizada, pois de acordo com Madalozzo (2008), os jogos entre times rivais geralmente são entre times da mesma cidade, o que faz com que fãs de ambos possam ir ao estádio, aumentando desta forma o público presente.
A variável "Vitória" foi acrescentada ao modelo sob a hipótese de que caso o time mandante tenha vencido uma maior proporção nos últimos três jogos, irá atrair mais torcedores ao estádio. Esta variável está incluída entre os fatores que explicam a relevância da performance atual do clube sobre a demanda por ingressos quando este joga em casa.

A variável "Capacidade" aparece no modelo com a hipótese "de que arenas maiores atendem clubes com maior demanda, seja por possuir maior torcida, estar localizado em cidades mais populosas ou por outros fatores não identificados.” (SOUZA, 2004, p. 61).

A variável "Promovido" foi acrescentada ao modelo sob a hipótese de que o time que conseguiu ascensão na temporada anterior atrai um maior público para a temporada atual.

Clubes como Flamengo, Corinthians, São Paulo, Palmeiras, Vasco, Botafogo e Fluminense apresentam uma torcida com mais de $40 \%$ fora de seus estados de origem. Assim, assume-se a hipótese de jogos em que esses times são visitantes, afetam significativamente a demanda por jogos do campeonato brasileiro, independente da série disputada. Desta forma a variável Grande será acrescentada ao modelo.

Com relação à Inglaterra, a variável Grande foi utilizada para os clubes com maior número de títulos do campeonato inglês, sendo eles: Manchester United, Liverpool e Arsenal.

Posição é uma variável que representa a colocação do time da casa no jogo $i$ e foi utilizada sob a hipótese de que quanto mais longe das primeiras colocações menor será a demanda.

Para captar o efeito de avanço do campeonato, foi utilizada a variável referente à rodada em que partida ocorreu, sob a hipótese de ao se aproximar do fim do campeonato, a demanda por jogos aumenta, visto que as partidas se tornam mais decisivas.

Como custo dos torcedores em irem assistir aos jogos nos estádios, o valor da passagem de ônibus na cidade em que a partida foi realizada foi utilizada como proxy para o Brasil. Já na Inglaterra, esse custo foi medido pelo preço da torta, pois os torcedores têm o hábito de comprá-la em dia de jogo, tanto que seu custo é adicionado ao custo de ir ao estádio, de acordo com a BBC Survey (2012).

No Brasil, devido à realização do Copa do Mundo de 2014, doze estádios foram reformulados ou construídos com os novos conceitos de arenas, que 
trazem mais conforto e segurança aos torcedores. Em 2013, seis destes estádios tiveram jogos do campeonato brasileiro. Desta forma, será utilizada uma dummy para caso de a partida ter ocorrido em uma dessas arenas.

O tamanho da torcida também está presente no modelo, para captar a capacidade de mercado. Assim, foi utilizado o tamanho da torcida do time da casa. Esta variável não pôde ser utilizada para o campeonato inglês devido sua indisponibilidade durante a pesquisa.

A variável PFC relaciona-se à porcentagem de assinantes, por estado, do canal pay-per-view Premiere Futebol Clube, que faz transmissões de jogos do campeonato brasileiro de futebol, funcionando, assim, como um bem substituto da venda de ingressos. Para a Inglaterra, devido à indisponibilidade de dados sobre os assinantes de canais pagos de futebol, utilizou-se o preço dos ingressos de cinema no dia e horário do jogo, como proxy para um bem substituto.

Uma dummy referente à chance de o time da casa se classificar para a Libertadores, foi empregada no modelo brasileiro. A mesma variável foi utilizada para o modelo inglês, captando o impacto da chance de se classificar para a Champions League na demanda por partidas do campeonato inglês.

Foram acrescentadas também variáveis referentes à diferença de pontos e posição dos times envolvidos na partida e o quadrado destas variáveis, pois, de acordo com Souza (2004), a relação entre essas variáveis é quadrática. E, como afirma Bortuluzzo, Laropoli e Machado (2011), esta variável é importante, pois a importância do jogo para o time da casa é relevante para entender a demanda por ingressos. Logo, esperase que quanto menor a diferença de posição e pontos entre os times, maior será a procura por ingressos.

Por último, foram acrescentadas dummies para caso o jogo tenha ocorrido no fim de semana e à tarde, pois, como afirmam García e Rodríguez (2001), o horário e dia da realização da partida são importantes para explicação da demanda.

O quadro 1 traz uma síntese com as variáveis explicativas usadas no modelo econométrico, o(s) autor(es) em que estão embasadas, a forma em que os dados foram tratados e o efeito esperado em ambos países.

Dobson e Goddard (2001) relatam que o fato de os dirigentes poderem discriminar preço antes das partidas faz com que esta variável se correlacione com o distúrbio aleatório $\varepsilon_{i}$, o que viola um dos pressupostos da análise de regressão, introduzindo um possível viés de simultaneidade na estimação. Este problema de simultaneidade da variável preço ocorre na equação de demanda por futebol a menos que a curva de oferta por futebol seja perfeitamente elástica.

García e Rodríguez (2001) também abordam a endogeneidade da variável preço. Assim, segundo Murray (2006), quando há correlação entre a variável explicativa e o distúrbio aleatório, são necessárias variáveis instrumentais que evitem o viés dos estimadores por mínimos quadrados ordinários. Ainda de acordo com Murray (2006), o método dos mínimos quadrados de dois estágios é o mais utilizado entre os econometricistas para solucionar o problema de endogeneidade.

Os modelos foram então estimados pelo método de Mínimos Quadrados de Dois Estágios (MQ2E) devido a endogeneidade da variável preço. Para o Brasil, foram utilizadas como instrumentos todas as variáveis da equação de demanda com a inserção de mais três instrumentos, sendo eles: a proporção entre o número de meias-entradas vendidas e número de ingressos vendidos, bem como a proporção do número de sócios torcedores e os ingressos vendidos e a razão entre o número de ingressos colocados à venda e a capacidade do estádio em que a partida foi realizada.

Desta forma, no primeiro estágio, a variável preço será estimada em relação às demais variáveis do modelo da equação de demanda adicionando-se os seguintes instrumentos: razão entre o número de meias-entradas vendidas e o total de público pagante, razão entre o número de sócios-torcedores e o total de público pagante, razão entre o número de ingressos colocados à venda e a capacidade do estádio em que a partida foi realizada e o tamanho da população da cidade em que o jogo ocorreu. O preço estimado nesta etapa foi utilizado no segundo estágio, já na equação de demanda. Ilustrativamente, tem-se:

1) Preço $_{i}=\alpha_{0}+\alpha_{1} Z_{1 i}+\alpha_{2} Z_{2 i}+\alpha_{3} Z_{3 i}+\beta_{1} X_{1 i}+\beta_{2} X_{2 i}+\cdots+\beta_{19} X_{19 i}+\eta_{i}$

(1)

2) Público $_{i}=\alpha_{0}+\alpha_{1} \widehat{\text { Preçco }_{1 i}}+\alpha_{2} X_{2 i}+\alpha_{3} X_{3 i}+\alpha_{4} X_{4 i} \ldots+\alpha_{19} X_{19 i}+\varepsilon_{i}$ (2)

sendo $\mathrm{Z}$ as variáveis instrumentais utilizadas para estimar o preço, $\mathrm{X}$ são as variáveis da equação de demanda e $\mathrm{Preço}_{i}$ o preço estimado no primeiro estágio.

Para a Inglaterra, foi estimado o mesmo modelo, mas, devido a incompatibilidade de disponibilidade 
de dados, foram utilizados como instrumentos, além de todas as variáveis da equação de demanda, a média de público no campeonato anterior, a posição do clube na temporada passada e se a partida tiver ocorrido no inverno.

Quadro 1- Síntese das variáveis utilizadas no modelo econométrico

\begin{tabular}{|c|c|c|c|}
\hline $\begin{array}{c}\text { Variáveis } \\
\text { explicativas }\end{array}$ & Referencial teórico & Operacionalização & $\begin{array}{c}\text { Efeitos } \\
\text { esperados }\end{array}$ \\
\hline $\begin{array}{l}\text { Log } \\
\text { (Preço) }\end{array}$ & $\begin{array}{l}\quad \text { Dobson e Goddard } \\
\text { (2001); García e Rodríguez } \\
\text { (2001); Madalozzo (2008) } \\
\text { e Bortoluzzo, Laropoli e } \\
\text { Machado (2011) }\end{array}$ & $\begin{array}{l}\text { Será usado o preço médio (razão } \\
\text { entre a arrecadação total da bilheteria } \\
\text { no jogo analisado e o público } \\
\text { pagante total). Para Inglaterra, será } \\
\text { utilizado o club day match. }\end{array}$ & - \\
\hline $\begin{array}{l}\text { Log } \\
\text { (Renda) }\end{array}$ & $\begin{array}{l}\text { García e Rodríguez (2001); } \\
\text { Souza (2004); Madalozzo } \\
\text { (2008) e Bortoluzzo, } \\
\text { Laropoli e Machado } \\
\text { (2011) }\end{array}$ & $\begin{array}{l}\text { Será usada a renda média por } \\
\text { domicílio da cidade em que a partida } \\
\text { ocorreu }\end{array}$ & - \\
\hline Rival & $\begin{array}{l}\text { Souza (2004); Madalozzo } \\
\text { (2008) e Bortoluzzo, } \\
\text { Laropoli e Machado } \\
\text { (2011) }\end{array}$ & $\begin{array}{l}\text { Será utilizada uma dummy com valor } \\
1 \text { para o caso de os times serem da } \\
\text { mesma cidade e } 0 \text { caso contrário }\end{array}$ & + \\
\hline Vitória & $\begin{array}{l}\text { García e Rodríguez (2001); } \\
\text { Souza (2004), Madalozzo } \\
\text { (2008) e Bortoluzzo, } \\
\text { Laropoli e Machado } \\
\text { (2011) }\end{array}$ & $\begin{array}{l}\text { Será usado o No. de vitórias do time } \\
\text { da casa nos últimos três jogos }\end{array}$ & + \\
\hline $\begin{array}{l}\text { Log } \\
\text { (Capacidade) }\end{array}$ & $\begin{array}{l}\text { Souza (2004); Madalozzo } \\
\text { (2008) e Bortoluzzo, } \\
\text { Laropoli e Machado } \\
(2011)\end{array}$ & $\begin{array}{l}\text { Será utilizada a capacidade do estádio } \\
\text { em que o jogo ocorreu }\end{array}$ & + \\
\hline Grande & $\begin{array}{l}\text { Souza (2004); Madalozzo } \\
\text { (2008) e Bortoluzzo, } \\
\text { Laropoli e Machado } \\
\text { (2011) }\end{array}$ & $\begin{array}{l}\text { Será utilizada uma dummy com } \\
\text { valor } 1 \text { para caso o time visitante } \\
\text { seja Flamengo, Corinthians, São } \\
\text { Paulo, Palmeiras, Vasco, Botafogo ou } \\
\text { Fluminense }\end{array}$ & + \\
\hline Promovido & $\begin{array}{l}\quad \text { Dobson e Goddard } \\
\text { (2001); Souza (2004); } \\
\text { Madalozzo (2008) e } \\
\text { Bortoluzzo, Laropoli e } \\
\text { Machado (2011) }\end{array}$ & $\begin{array}{l}\text { Será utilizada uma dummy com valor } \\
1 \text { caso o time mandante tenha sido } \\
\text { promovido na temporada anterior e } \\
0 \text { caso contrário }\end{array}$ & + \\
\hline PFC & - & $\begin{array}{l}\text { Será utilizado a \% de assinantes do } \\
\text { canal Premiere Futebol Clube, por } \\
\text { estado }\end{array}$ & - \\
\hline Rodada & Souza (2004) & $\begin{array}{l}\text { Será utilizado o No. da rodada em } \\
\text { que a partida ocorreu }\end{array}$ & + \\
\hline
\end{tabular}




\begin{tabular}{|c|c|c|c|}
\hline Fim & $\begin{array}{l}\text { Madolozzo(2008); } \\
\text { Bortoluzzo, Laropoli e } \\
\text { Machado (2011) }\end{array}$ & $\begin{array}{l}\text { Será utilizado uma dummy com valor } \\
1 \text { caso o jogo ocorra no final de } \\
\text { semana e } 0 \text { caso contrário }\end{array}$ & \\
\hline Posição & \begin{tabular}{l}
\multicolumn{1}{c}{ Dobson e Goddard } \\
(2001); Madalozzo (2008); \\
Bortoluzzo, Laropoli e \\
Machado (2011)
\end{tabular} & $\begin{array}{l}\text { Será utilizada a posição na tabela do } \\
\text { time mandante da partida }\end{array}$ & - \\
\hline Pontos & Souza (2004) & $\begin{array}{l}\text { Será utilizada a diferença de pontos } \\
\text { até a realização da partida entre o } \\
\text { time mandante e visitante }\end{array}$ & - \\
\hline Pontos2 & Souza (2004) & $\begin{array}{l}\text { Será dada pelo quadrado da variável } \\
\text { Pontos }\end{array}$ & + \\
\hline Amplitude & $\begin{array}{l}\text { García e Rodríguez (2001); } \\
\text { Souza (2004) }\end{array}$ & $\begin{array}{l}\text { Será utilizada a diferença entre } \\
\text { posições do time mandante/visitante } \\
\text { durante a partida }\end{array}$ & - \\
\hline Amplitude2 & $\begin{array}{l}\text { García e Rodríguez (2001); } \\
\text { Souza (2004) }\end{array}$ & $\begin{array}{l}\text { Será dada pelo quadrado da variável } \\
\text { amplitude }\end{array}$ & + \\
\hline $\begin{array}{l}\text { Log } \\
\text { (Torcida) }\end{array}$ & - & $\begin{array}{l}\text { Será utilizado o No. de torcedores } \\
\text { do time da casa, no estado em que o } \\
\text { jogo ocorreu }\end{array}$ & + \\
\hline $\begin{array}{l}\text { Log } \\
\text { (Passagem) }\end{array}$ & - & $\begin{array}{l}\text { Será utilizado o preço médio da } \\
\text { gasolina cobrado no estado em que o } \\
\text { jogo ocorreu }\end{array}$ & - \\
\hline Arenas & - & $\begin{array}{l}\text { Será utilizada uma dummy com valor } \\
1 \text { caso a partida tenha sido realizada } \\
\text { em dos novos estádios brasileiros }\end{array}$ & + \\
\hline $\begin{array}{l}\log \\
\text { (pie) }\end{array}$ & - & $\begin{array}{l}\text { Será utilizado o logaritmo do preço } \\
\text { da torta nos estádios ingleses }\end{array}$ & - \\
\hline $\begin{array}{l}\text { Libertadores e } \\
\text { Champions }\end{array}$ & $\begin{array}{l}\text { Madalozzo (2008); } \\
\text { Bortoluzzo, Laropoli e } \\
\text { Machado (2011) }\end{array}$ & $\begin{array}{l}\text { Será utilizada um dummy com } \\
\text { valor } 1 \text { caso o time esteja entre os } \\
\text { seis primeiros colocados e } 0 \text { caso } \\
\text { contrário }\end{array}$ & + \\
\hline
\end{tabular}

Fonte: Elaboração própria dos autores.

\section{Análise dos resultados}

Esta seção consiste em fazer uma avaliação dos resultados obtidos na equação de demanda estimada por MQ2E para os jogos dos campeonatos brasileiro e inglês de 2013. E divide-se em duas subseções, a primeira traz uma análise dos fatores econômicos, bem como uma comparação entre o comportamento dos clubes brasileiros e ingleses como maximizadores de lucros. A segunda subseção se atém a analisar os resultados referentes à qualidade da partida e incerteza do resultado.

\section{Fatores econômicos e implicações na maximização de lucros}

As variáveis utilizadas no grupo de fatores econômicos, preço e renda, mostraram-se estatisticamente significantes ao nível de 5\%, tanto para o Brasil quanto para Inglaterra. 
O preço apresentou uma elasticidade de $-0,72$ para o campeonato brasileiro e $-0,97$ para o inglês. Assim, o futebol é um inelástico em relação ao preço. Isto significa que do ponto de vista da teoria do consumidor, os torcedores tanto no Brasil quanto na Inglaterra são pouco sensíveis às variações no preço dos ingressos, visto que um aumento neste fator reduz menos que proporcionalmente a demanda.

Do ponto de vista da firma, no caso os clubes de futebol, os times ingleses são mais eficientes que os brasileiros no que tange às receitas provenientes $\mathrm{da}$ venda de ingressos, visto que na Inglaterra a elasticidade-preço da demanda está mais próxima de 1 , valor em que a receita para de variar positivamente dada uma variação positiva no preço. A explicação matemática para isto pode ser vista em Varian (2006), que afirma haver uma relação estreita entre receita e elasticidade-preço, sendo definida a receita como:

$$
R=p \cdot q
$$

Se preço e receita variarem para $\mathrm{p}+\Delta \mathrm{p}$ e $\mathrm{q}+\Delta \mathrm{q}$, respectivamente, a nova receita será de:

$$
R^{\prime}=(p+\Delta \mathrm{p})(\mathrm{q}+\Delta \mathrm{q})
$$

Subtraindo R de R', tem-se:

$$
\Delta \mathrm{R}=\mathrm{q} \Delta \mathrm{p}+\mathrm{p} \Delta \mathrm{q}
$$

Para obtermos a relação entre receita e preço, basta apenas dividir a equação (5) por $\Delta \mathrm{p}$, para obter:

$$
\frac{\Delta \mathrm{R}}{\Delta \mathrm{p}}=q+\frac{\Delta \mathrm{q}}{\Delta \mathrm{p}}
$$

Para Varian (2006) a receita irá variar positivamente

$$
\frac{p}{q} \frac{\Delta \mathrm{q}}{\Delta \mathrm{p}}>-1
$$

O lado esquerdo da equação (7) nada mais é do que a elasticidade-preço da demanda. Assim, tem-se que a receita varia positivamente quando:

$$
|\varepsilon(p)|<1
$$

Os resultados obtidos referentes ao preço corroboram aqueles encontrados por Dobson e Goddard (2001), Madalozzo (2008) e Bortoluzzo, Laropoli e Machado (2011), ao mostrar que a demanda por futebol é inelástica nos dois países.

Com relação à renda, houve divergência entre os resultados encontrados no Brasil e na Inglaterra.
Neste, o futebol mostrou ser um bem inferior, com elasticidade de $-0,15$, enquanto naquele o bem é normal, ou seja, um aumento na renda do consumidor causa um aumento no consumo por futebol. Este resultado diverge dos resultados encontrados em Souza (2004), Madolozzo (2008) e Bortoluzzo, Laropoli e Machado (2011). Este efeito positivo pode ter sido gerado pela introdução da variável Arena ao modelo. Assim, esse novo conceito de praças esportivas com mais conforto e segurança podem ter chamado mais atenção dos consumidores com rendas mais elevadas para conhecerem os novos estádios, com estruturas inéditas no Brasil.

$\mathrm{Na}$ Inglaterra, a introdução de novas arenas aconteceu em meados da década de 1990, encontrando-se, atualmente, em uma fase já madura, ou seja, os torcedores já não têm o interesse de irem aos jogos com o intuito de conhecerem os novos estádios, caso que está acontecendo no Brasil no presente momento. Assim, pode ser explicada a diferença entre o sinal das elasticidades-renda da demanda encontrada. Esperase então, que o futebol volte, nos próximos anos, a ser um bem inferior, assim como na Inglaterra.

\section{Qualidade da partida, substitutos e fatores estruturais}

Outros fatores estatisticamente significantes tanto para o Brasil quanto para a Inglaterra foi a capacidade dos estádios, mostrando que este fator afeta positivamente a procura por jogos nos dois países, sendo que na Inglaterra o impacto é maior. Uma das hipóteses a serem lançadas sobre o resultado é de que estádios com mais lugares geram mais conforto aos torcedores.

No Brasil, outros fatores que se mostraram estatisticamente significantes foram as variáveis referentes à rivalidade entre os clubes, o fato de o time visitante ser considerado grande e as novas arenas. Pode-se, então, perceber que os torcedores brasileiros são mais sensíveis aos aspectos relacionados aos clubes visitantes.

$\mathrm{Na}$ Inglaterra, o cinema mostrou ser um bem substituto do futebol. Outros fatores como a posição do time na tabela de classificação e o fato de a partida ser realizada no fim de semana afetam a demanda por jogos do campeonato inglês.

Os resultados apontam que, com relação aos fatores econômicos e estruturais, os consumidores, tanto no Brasil quanto na Inglaterra, agem da mesma forma, exceto para renda. Já em relação à qualidade esperada 
da partida e incerteza do resultado, os brasileiros são mais sensíveis que os ingleses.

A Tabela 2 traz os resultados da estimação do modelo por MQ2E para Brasil e Inglaterra.

Tabela 2- Resultado da estimação do modelo por MQ2E- Brasil (2013)

Variável dependente: Log Público

\begin{tabular}{|c|c|c|}
\hline Variáveis & Brasil & Inglaterra \\
\hline Constante & $\begin{array}{c}-2,389520 \\
(0,27)\end{array}$ & $\begin{array}{c}6,104953^{*} \\
(0,04)\end{array}$ \\
\hline Log(Preço) & $\begin{array}{c}-0,720222 \\
(0,050) *\end{array}$ & $\begin{array}{c}-0,972535^{*} \\
(0,04)\end{array}$ \\
\hline Log(Renda) & $\begin{array}{c}0,730711 \\
(0,012) *\end{array}$ & $\begin{array}{c}-0,155367 * \\
(0,04)\end{array}$ \\
\hline Promovido & $\begin{array}{c}0,239909 \\
(0,130)\end{array}$ & $\begin{array}{c}0,191950^{*} \\
(0,03)\end{array}$ \\
\hline PFC/Cinema & $\begin{array}{c}-0,045340 \\
(0,456)\end{array}$ & $\begin{array}{c}0,217686^{*} \\
(0,020)\end{array}$ \\
\hline Rodada & $\begin{array}{c}-0,000691 \\
(0,921)\end{array}$ & $\begin{array}{c}0,000836 \\
(0,557)\end{array}$ \\
\hline Fim & $\begin{array}{c}0,169207 \\
(0,067)\end{array}$ & $\begin{array}{l}0,049311 \\
(0,027) *\end{array}$ \\
\hline Rival & $\begin{array}{c}0,608143 \\
(0,000)^{*}\end{array}$ & $\begin{array}{c}0,006537 \\
(0,827)\end{array}$ \\
\hline Posição & $\begin{array}{c}-0,013309 \\
(0,406)\end{array}$ & $\begin{array}{c}-0,034501 \\
(0,009) *\end{array}$ \\
\hline $\begin{array}{c}\text { Libertadores/ } \\
\text { Champions }\end{array}$ & $\begin{array}{c}-0,021405 \\
(0,897)\end{array}$ & $\begin{array}{c}-0,087670 \\
(0,033) *\end{array}$ \\
\hline Pontos & $\begin{array}{c}-0,009489 \\
(0,653)\end{array}$ & $\begin{array}{c}-6,22 \mathrm{e}^{\wedge}-05 \\
(0,987)\end{array}$ \\
\hline Pontos2 & $\begin{array}{c}0,000321 \\
(0,593)\end{array}$ & $\begin{array}{c}-2,97 e^{\wedge}-05 \\
(0,669)\end{array}$ \\
\hline Grande & $\begin{array}{c}0,290017 \\
(0,018) *\end{array}$ & $\begin{array}{c}0,020576 \\
(0,371)\end{array}$ \\
\hline Amplitude & $\begin{array}{c}0,003176 \\
(0,933)\end{array}$ & $\begin{array}{c}-0,012291 \\
(0,262)\end{array}$ \\
\hline Amplitude2 & $\begin{array}{c}-0,000646 \\
(0,769)\end{array}$ & $\begin{array}{c}0,000949 \\
(0,144)\end{array}$ \\
\hline $\log ($ Torcida $)$ & $\begin{array}{l}0,284752 \\
(0,000) *\end{array}$ & - \\
\hline
\end{tabular}

\begin{tabular}{ccc} 
Arenas & 0,612901 & - \\
& $(0,017)^{*}$ & \\
$\log ($ Passagem $)$ & 0,208234 & - \\
& $(0,396)$ & \\
$\log ($ Capacidade $)$ & $0,306092^{*}$ & $0,832275^{*}$ \\
& $(0,010)$ & $(0,000)$ \\
\hline R-Squared & 0,297244 & 0,792084 \\
\hline
\end{tabular}

Fonte: Elaboração dos autores. * Significante ao nível de 5\%.

\section{Conclusões}

O futebol constitui uma atividade econômica muito significativa em vários países. Deve, portanto, ser estudado em uma perspectiva sistêmica, capaz de compreender toda sua cadeia produtiva. Devido ao montante envolvido na indústria do futebol e a participação pequena do Brasil nesta indústria, bem como a grande importância da Inglaterra neste setor, este estudo buscou identificar os fatores que influenciam a demanda por jogos dos campeonatos de futebol dos respectivos países, para que a partir dos resultados obtidos os agentes envolvidos na indústria em questão possam tomar medidas visando a maior eficiência financeira.

A partir de um modelo econométrico estimado por Mínimos Quadrados de Dois Estágios (MQ2E), foi possível encontrar alguns fatores que levam os torcedores aos estádios brasileiros e ingleses, cumprindo o objetivo geral deste trabalho.

Os resultados obtidos neste estudo corroboram as hipóteses anteriormente elencadas de que os torcedores ingleses são menos sensíveis aos aspectos dos times do que os brasileiros. Isto mostra que, na Inglaterra, os fãs de futebol que vão ao estádio são impulsionados apenas pelos aspectos referentes aos seus times e não do adversário, como ocorre no Brasil.

Em relação ao comportamento dos clubes como agentes maximizadores de lucro, os resultados corroboram a hipótese de que os clubes ingleses estão mais próximos da margem de maximização de lucro que os brasileiros, apresentando uma elasticidadepreço da demanda de $-0,97$. Este resultado também cumpre um dos objetivos específicos apresentados neste trabalho.

Ainda quanto aos objetivos específicos, os resultados encontrados foram suficientes para identificar de que maneira os fatores econômicos impactam a demanda 
por futebol no Brasil e na Inglaterra, bem como fatores estruturais, de qualidade da partida e substitutos.

Os resultados desta pesquisa mostram que as novas arenas construídas para Copa do Mundo 2014 aumenta, em média, $61 \%$ do público presente nos estádios brasileiros. Algo que ocorreu na década de 1990 na Inglaterra, com a reforma e construção de estádios modernos e que oferecem mais segurança e conforto aos espectadores. A tendência é de que o Brasil siga a Inglaterra neste ponto, em que a demanda irá aumentar nos primeiros anos e se estabilizar logo após.

A variável relacionada a capacidade dos estádios demonstram que ocupação média dos estádios na Inglaterra é maior que no Brasil. Isto pode ocorrer devido ao regionalismo e extensão territorial brasileiro, que faz com que, mesmo um time tenha uma grande torcida, a capacidade total do seu estádio não seja grande, pois este público está divido em várias regiões do Brasil. Enquanto na Inglaterra o regionalismo é mais forte, ou seja, a torcida é em sua maioria composta por moradores de dada região. Isso pode ser corroborado pelo resultado encontrado para variável Grande no Brasil.

Os achados deste estudo contribuem para o aumento da literatura sobre a Economia do Esporte, mostrando a importância do futebol como indústria. Contribuem, ainda, para que os agentes envolvidos nesta indústria possam tomar decisões mais eficientes, visando ao aumento de seus resultados. É possível verificar que no Brasil, por exemplo, se os clubes aumentarem o preço dos ingressos, aumentarão suas receitas.

As limitações encontradas neste trabalho consistem na indisponibilidade de dados para campeonatos anteriores, o que inviabilizou a extensão da pesquisa para um horizonte maior de tempo. Registra-se, também, a falta de informações sobre violência nos estádios brasileiros e ingleses, que pode ser um dos fatores mais importantes para explicar a presença de público.

Sugere-se que o estudo sirva de base comparativa para futuros trabalhos sobre a demanda por jogos do campeonato brasileiro e inglês. Há também a possibilidade de se verificar o impacto da Copa do Mundo FIFA 2014 na procura por partidas do campeonato brasileiro. Esta pesquisa pode, também, servir de parâmetro para estudos de campeonatos nacionais de outros países como Espanha, e Alemanha, que apresentam uma boa média de público nos estádios, analisando de que forma cada fator utilizado neste trabalho impacta a demanda por jogos nesses países.

\section{Referências}

AIDAR, A., FAULIN, E. O negócio do futebol. In: CAMPOS, C. et al. Futebol e desenvolvimento socioeconômico. Caderno FGV Projetos, n. 22, 2013, p. 46-61. Disponível em: <http:/ / fgvprojetos. fgv.br/publicacao/cadernos-fgv-projetos-no-22futebol-e-desenvolvimento-economico-social-0>. Acesso em: 20 de abril de 2014.

AIDAR, A. C. K.; LEONCINI, M. P. Evolução do futebol e do futebol como negócio. In: AIDAR, Antonio Carlos Kfouri; LEONCINI, Marvio Pereira; OLIVEIRA, José de Oliveira. A nova gestão do futebol. Rio de Janeiro: FGV, 2000. p. 79-101.

BARAJAS, A., FERNANDEZ-JARDON, C., \& CROLLEY, L. Does sports performance influence revenues and economic results in Spanish football? MPRA Munich Personal RePEc Archive. Edição de Julho. 2005. Disponível em: <http:/ / mpra.ub.unimuenchen.de/3234/>. Acesso em: 20 de abril de 2014.

BBC SPORTS SURVEY. The price of football. Disponível em: <http://www.bbc.com/sport/0/ football/24052562 >. Acessado em: 23/02/2014.

BEAMON, B. M. Measuring supply chain performance. International Journal of Operations \& Production Management, v. 19, n. 3, p. 275-292, 1999.

BELO, Eduardo; PAOLOZZI, Vitor. Futebol faz 150 anos e movimenta até US\$ 1 tri. Ano 14, n.3371, out, 2013.Disponível em: <http:/ /www.cliptvnews. com.br/mma/adm/imagens/pdf/1382693074_img. pdf $>$. Acessado em: 28/10/2013.

BLUMENSCHEIN, F. A Cadeia Produtiva do Futebol no Brasil. p. 78-85. in CAMPOS, C., et al. Futebol e desenvolvimento socioeconômico. Caderno FGV Projetos, n. 22, 2013. Disponível em: < http:// fgvprojetos.fgv.br/publicacao/cadernos-fgv-projetosno-22-futebol-e-desenvolvimento-economicosocial-0 > . Acesso em: 20 de abril de 2014.

BORLAND, J. The demand for australian rules football. Economic Record, v. 63, n. 3, p. 220 230,1987. Disponível em: <http:// onlinelibrary.wiley. com/doi/10.1111/j.1475-4932.1987.tb00653.x/ abstract>. Acesso em: 20 de abril de 2014.

BORTOLUZZO, Adriana Bruscato; LAROPOLI, Pedro Trindade; MACHADO, Sérgio Jurandyr. 
Demand for Brazilian soccer: A censored model approach. Insper Working Paper, v. 237, p. 1-18, 2011.

\section{BRUSTOLIN, Maurício Pizzolatto. Contrato} de trabalho do atleta profissional de futebol. Monografia. Universidade do Vale do Itajaí-UNIVALI. Itajaí, SC. 2008. Disponível em:<http:// siaibib01. univali.br/pdf/Mauricio\%20Pizzolatto\%20Brustolin. pdf>. Acessado em: 09/06/2015.

BURAIMO, B., \& SIMMONS, R. Market size and attendance in English Premier League football. International Journal of Sport Management and Marketing. v. 6, n. 2, p. 200-214, 2009.

CARVALHO, C. A. P.; GONÇALVES, J. C. S.; ALCÂNTARA, B. C. S. A Transformação do Futebol: da Diversão à Hegemonia do Mercado. In: ENCONTRO NACIONAL DOS PROGRAMAS DE PÓS-GRADUAÇÃO EM ADMINISTRAÇÃO. Anais... EnANPAD, 2003.

CONFEDERAÇÃO BRASILEIRA DE FUTEBOL. Competições. Disponível em: <http://www. cbf.com.br/Competi $\% \mathrm{C} 3 \% \mathrm{~A} 7 \% \mathrm{C} 3 \% \mathrm{~B} 5 \mathrm{es} /$ S\%C3\%A9rie\%20A/Tabela/2012>. Acessado em: 20/02/2014.

CONFEDERAÇÃO BRASILERIA DE FUTEBOL. Cadastro Nacional de Estádios de Futebol.

Disponível em: <http:/ /www.cbf.com.br/cnef/cnef. pdf $>$. Acessado em 22/02/2014.

DELL'OSSO, F.; SZYMANSKI, S. Who are the champions? An analysis of football and architecture. Business Strategy Review Summer, v. 2, n. 2, 113-130, 1991. Disponível em: < http:/ / onlinelibrary.wiley.com/doi/10.1111/j.1467-8616.1991. tb00155.x/abstract?deniedAccessCustomisedMessage $=$ \&userIsAuthenticated $=$ false $>$. Acesso em: 20 de abril de 2014.

\section{DELOITTE. All to play for. Football Money}

League, 2014. Disponível em: < http:/ / www.deloitte.com/view/en_GB/uk/industries/sportsbusinessgroup/sports/football/deloitte-football-money-league/index.htm $>$. Acesso em: 20 de abril de 2014.

DELLOITE. Relatório. Disponível em: < http:/ / www.deloitte.com/view/pt_PT/pt/servicos/consulting/18a0454c5286c310VgnVCM2000003356f70aRCRD.htm>. Acessado em 01/12/2013.
DOBSON, Stephen; GODDARD, John. The economics of football. Cambridge: Cambridge University Press, 2001.

DOBSON, Stephen; GODDARD, John. Revenue divergence and competitive balance in a divisional sports league. Scottish Journal of Political Economy, v.51, n.3, p.359-376, 2004.

EKELUND, P. A rentabilidade das associações de times de futebol: os exemplos das ligas de futebol da Itália e da Inglaterra. São Paulo: FGV, 1998.

FAGUNDES, A. F. A.; VEIGA, R. T. Fatores que influenciam a satisfação dos torcedores na ida aos estádios de futebol no Brasil e sua intenção de retorno. Acessado em: 07/05/2014. 2013.

FLEURY, F. A., CARDOSO, M. V., FOUTO, N. M. D., \& VANCE, P. S. Estratégias de relacionamento entre clubes e torcedores de futebol no Brasil: aumento do consumo do torcedor explorando a fidelidade à marca. In: ENCONTRO NACIONAL DOS PROGRAMAS DE PÓS GRADUAÇÃO EM ADMINISTRAÇÃO. Anais...EnANPAD, 2013.

GARCÍA, Jaime; RODRÍGUEZ, Plácido. The determinants of football match attendance revisited: empirical evidence from the Spanish football league. Economics Working Papers from Department of Economics and Business, University Pompeu Fabra, 2001. Disponível em: < http://www. econ.upf.edu/docs/papers/downloads/555.pdf>. Acessado em: 30/03/2014.

GIL, Antônio Carlos.Como elaborar projetos de pesquisa. 5. ed. São Paulo: Atlas, 2010.

GRELLET, C. Copa 2014 e clubes de futebol no Brasil. In: CAMPOS, C. et al. Futebol e desenvolvimento econômico-social. Cadernos FGV Projetos, n.19, p. 53-56, 2010.

GUJARATI, Damodar. Econometria básica. São Paulo: Makron Books, 2002.

HART, R.A; HUTTON, J.; SHAROT, T. A statistical analysis of association football attendances. Applied statistics: a journal of the royal statistical society, v.24, n.1, p.17-27. 1975.

INSTITUTO BRASILEIRO DE GEOGRAFIA E ESTATÍSTICA. IBGE Cidades@. Disponível em: $<$ http://www.ibge.gov.br/cidadesat/index.php>. Acessado em: 23/02/2014.

LANGONI, C. Combinando o talento dentro e fora do campo: transformações econômicas e mudanças 
estruturais no futebol. p. 39-45. In: CAMPOS, C. et al. Futebol e desenvolvimento socioeconômico. Caderno FGV Projetos, n. 22, 2013. Disponível em: <http:/ / fgvprojetos.fgv.br/publicacao/cadernos-fgv-projetosno-22-futebol-e-desenvolvimento-economicosocial-0>. Acesso em: 20 de abril de 2014.

LEONCINI, M. P. Entendendo o negócio

futebol: um estudo sobre a transformação do modelo de gestão estratégica nos clubes de futebol. Tese de doutorado. Programa de Pós-graduação em Engenharia de Produção. Universidade de São Paulo, 2001.

LEONCINI, Marvio Pereira; SILVA, Márcia Terra da. Entendendo o futebol como negócio: um estudo exploratório. Revista Gestão e Produção, v. 12, n. 1, p.11-23. 2005.

MADALOZZO, Regina. A model of attendance demand at the brazilian football league. Insper Working Paper. WPE: 113/2008. 2008.

MÁXIMO, João. Memórias do futebol brasileiro. Estudos avançados, São Paulo, v.13, n.37, 1999. Disponível em: < http:/ /www.scielo.br/scielo. php?pid $=$ S0103-40141999000300009\&script $=$ sci_ arttext >. Acessado em: 10/06/2015.

MOSCA, H. M. B.; SILVA, J. R. G.; BASTOS, S. A. P. Fatores institucionais e organizacionais que afetam a gestão profissional de departamentos de futebol dos clubes: o caso dos clubes de futebol no Brasil. Revista Gestão \& Planejamento, v. 10, n. 1, p. 53-71, 2009.

MURRAY, Michael P. Econometrics: a modern introduction. Boston: Pearson, 2006.

O'CONNOR, Joseph Gerald. Do league ranking, promotion and relegation affect football stadium attendance? An empirical investigation into the English football league, University of Nottingham, 2009.

OFFICE FOR NATIONAL STATISTICS.

Economy. Disponível em: < http://www. statistics.gov.uk/hub/index.html >. Acessado em: 24/02/2014.

PINDYCK, Robert S.; RUBINFELD, Daniel L. Microeconomia. 7. Boston: Pearson, 2009.

PLURICONSULTORIA, Relatório. Disponível em: <http://www.pluriconsultoria.com.br/relatorios. php>. Acessado em: 20/12/2013.

REALE, G.; DALMORO, M.; SEGABINAZZI, R.
C. Paixão pelo consumo e consumo pela paixão: o processo de comoditização do mercado de futebol brasileiro. In: Encontro Nacional dos Programas de Pós-Graduação em Administração. Anais... EnANPAD, 2013.

RICHARDSON, Roberto Jarry. Pesquisa social: métodos e técnicas. 3. ed, São Paulo: Atlas, 2007.

RODRIGUES, M. S.; SILVA, R. F. C. Os mercadores de emoção: um estudo sobre a empresarização de clubes de futebol no Brasil e sua configuração estrutural. In: RODRIGUES, Marcio Silva. Os mercados de emoção: um estudo sobre a empresarização de clubes de futebol no Brasil e sua configuração estrutural. Dissertação de mestrado. Pós-Graduação em administração. Universidade Federal de Santa Catarina. Disponível em: < https://repositorio.ufsc. br/bitstream/handle/123456789/89123/225195. pdf? sequence $=1>$. Acessado em: 07/05/2014. 2007

RODRIGUES, M.; SILVA, R.; DELLAGNELO, E. O processo de empresarização em organizações culturais brasileiras. RPCA, Rio de Janeiro, v. 8, n. 1, p. 66-85, jan./mar, 2014.

ROTTENBERG, S. The baseball players' labor market. Journal of Political Economy, v. 62, p. 242-258, 1959.

RUSSEL, Micheal. The origin of soccer.

Disponível em < http:/ / ezinearticles.com/?TheOrigin-of-Soccer\&id $=244527>$. Acessado em: 09/06/2015

SANTANA, E. E. P.; SOBRINHO, Z. A. Um modelo conceitual sobre a influência do amor à marca no comportamento do consumidor no concernente à indústria do futebol. In: ENCONTRO NACIONAL DOS PROGRAMAS DE PÓS-GRADUAÇÃO EM ADMINISTRAÇÃO. Anais...... EnANPAD, 2008.

SANTANA, E. E. P.; SOBRINHO, Z. A. Amor à marca: um estudo sobre seus conseqüentes e antecedentes com torcedores-consumidores de futebol. In: SANTANA, Élcio Eduardo de Paula. $\mathrm{O}$ amor à marca e seu relacionamento com algumas variáveis que o antecedem e o sucedem: um estudo sob ótica de torcedores-consumidores de times de futebol brasileiros. Tese de doutorado. Curitiba. 2009. Disponível em: < http://dspace.c3sl. ufpr.br/dspace/bitstream/handle/1884/21407/ Tese-Final_ElcioSantana.pdf?sequence $=1>$. Acessado em: 07/05/2014. 
SANTOS, J. M. C. M. O torcedor e o consumo de partidas de futebol: uma visão histórica de um fenômeno cultural no Brasil na primeira metade do século XX. In: Encontro Nacional dos Programas de Pós-Graduação em Administração. Anais... EnANPAD, 2013.

SILVA, Edna L.; MENEZES, Estera M. Metodologia da pesquisa e elaboração de dissertação. Universidade Federal de Santa Catarina, Florianópolis, 2001.

SOLÉ, Andreu. ¿Qué es una empresa? Construcción de un idealtipo transdisciplinario. Working Paper.

Paris, 2004. L'enterprisation du monde. In: CHAIZE, J.; TORRES, F. Repenser l'entreprise: Saisir ce qui commence, vingt regards sur une idée neuve. Paris: Le Cherche Midi, p. 27-54, 2008.

SOUZA, F. A. P. Um estudo sobre a demanda por jogos de futebol nos estádios brasileiros. Dissertação de mestrado. Departamento de Administração, FEA-USP, 2004. Disponível em: <http://www.teses.usp.br/teses/ disponiveis/12/12139/tde-21072004-151604/pt-br. php>. Acessado em: 31/01/2014.

VALENTE, R.; SERAFIM, M. C. Gestão esportiva: novos rumos para o futebol brasileiro. Revista de

Administração de Empresas, v. 46, n. 3, p. 131-36, 2006.

VARIAN, Hal. R. Microeconomia: uma abordagem moderna. 7. ed. Rio de Janeiro: Elsevier, 2006.

WORLD FOOTBALL. Results \& Tables.

Disponível em: <http://www.worldfootball.net/ competition/eng-premier-league/>. Acessado em: 24/02/2014. 